\title{
Differences in Quality of Life and Compliance with Diet in Children with Celiac Disease in Slovak Republic
}

\author{
Kvetoslava Rimarova, ${ }^{1,2, *}$ \\ ${ }^{1}$ Institute of Public Health, University of P. J. Safarik, Faculty of Medicine, Košice Slovakia \\ ${ }^{2}$ Association of Parents, Friends of Children and Youth with Celiac Disease in Košice, Slovakia \\ *Corresponding author: kvetoslava.rimarova@upjs.sk
}

Received November 01, 2014; Revised November 05, 2014; Accepted November 11, 2014

\begin{abstract}
Celiac disease is chronic disease with immune disorder which is connected with the allergy reaction on molecule of gluten and prolamine. Celiac disease is expressed in persons with genetic susceptibility. The aim of the study was to follow adherence to gluten-free diet. We designed cross-sectional study where was recruited 125 volunteers, children at age 9 - 15 years old, with diagnosis of celiac diseases confirmed by European Society for Pediatric Gastroenterology Hepatology and Nutrition criteria. The data were collected in 2012-2013. In the selected group of celiac children were 78 girls and 47 boys. Compliance with diet is statistically significantly higher among girls comparing to boys. It means that girls adhered diet better than boys. Also younger group of children have a little bit higher compliance with gluten-free diet comparing to older group, but OR was not statistically significant. Our outputs didn't confirm fact that duration of disease is important factor which may influence the compliance with gluten-free diet, but more close is a relationship in diet compliance in children with shorter duration of disease.
\end{abstract}

Keywords: celiac disease, children, adherence to diet, gluten-free diet

Cite This Article: Kvetoslava Rimarova, "Differences in Quality of Life and Compliance with Diet in Children with Celiac Disease in Slovak Republic." International Journal of Celiac Disease, vol. 2, no. 4 (2014): 131-133. doi: 10.12691/ijcd-2-4-5.

\section{Introduction}

Celiac disease (CD) is chronic autoimmune disorder of the small intestine that occurs in genetically predisposed people of all ages from middle infancy onward. Symptoms include pain and discomfort in the digestive tract, chronic constipation and diarrhea, growth stunting, anemia and fatigue. Vitamins, minerals and nutrients deficiencies are often noted in people with coeliac disease owing to the reduced ability of the small intestine to properly absorb nutrients from food [1]. At present, the only effective treatment is a lifelong gluten-free diet [2]. No medication exists that will prevent damage or prevent the body from attacking the gut when gluten is present. Strict adherence to the diet allows the intestines to heal, leading to resolution of all symptoms in most cases and, depending on how soon the diet is begun, can also eliminate the heightened risk of osteoporosis and intestinal cancer and in some cases sterility [3]. The diet can be cumbersome; failure to comply with the diet may cause relapse.

Regarding quality of life of celiac people there have been several studies of quality of life in the group of $C D$ patients. Some of them focused on adult population $[4,5]$ some on children's group [6,7]. Usually CDs is diagnosed and developed through childhood and this chronic disorder can negatively impact all aspects of health and wellbeing - physical, social and psychological. We suppose that is very important to discover and confirm the extent to which celiac children suffer as a result of the disease. Scientific studies comparing quality of life in patients with $\mathrm{CD}$ have conflicting and different results. Some studies $[7,8,9,10]$ confirmed that quality of life was almost on the same level as the general population, other reference studies confirm decreased quality of life particularly in mental and social areas [11]. The aim of our study was to compare gender difference in quality of life in Slovak celiac children. We tried to compare difference between boys and girls in quality of life and wellbeing using personal questionnaire and clinical data which confirmed diagnosis.

\section{Material and Methods}

We designed cross-sectional study where was recruited 125 volunteers, children at age 9 - 15 years, with diagnosis of CDs confirmed by ESPGHAN (European Society for Pediatric Gastroenterology Hepatology and Nutrition) criteria [12]. The data were collected in 2012-2013. In the selected group of celiac children were 78 girls and 47 boys. Data for questionnaires were collected in outpatient gastroenterology department. Selected children obtained questionnaires modified to their school age to assess physical, social, psychological wellbeing and compliance with diet. Children questionnaires were anonymous and separate sheet confirmed prior signed agreement of parents or tutor of the child. Some questions have been added specifically to $\mathrm{CD}$ questions concerning lifestyle, 
chronic additional symptoms in children, lengths of gluten-free diet and adherence to diet. Database was created and statistically analyzed in software IBM-SPSS version 16. Statistical differences between selected parameters were expressed as OR with $95 \%$ CI.

\section{Results}

Data from 125 questionnaires have been analyzed, totally in the group were 47 boys and 78 girls, mean age 11.33 years. Strict gluten-free diet was maintained by $73.6 \%$ of children, less frequent was worse compliance with diet (non-strict diet or some gluten) - 26.4\%. Most of children - $66.4 \%$ - have shorter duration of disease within 0-6 years and almost half of children had persisting chronic gastrointestinal symptoms (Table 1).

OR are calculated for the group of boys, younger children and children with short duration of disease. This study suggests that children adapt well to $\mathrm{CD}$ and required diet, compliance with diet is statistically significantly better among girls comparing to boys. It means that girls adhered diet better than boys. Also younger group of children have a little bit better compliance with gluten-free diet comparing to older group, but OR was not statistically significant. Our outputs didn't confirm fact that duration of disease is important factor which may influence the compliance with gluten-free diet, better results in compliance are in children with shorter duration of disease. The study didn't collected data from parent opinions. Parents of celiac children could be at risk of overtreatment of the psychological, social and physical impacts of the disease on child perception. It is important that parents of celiac children let their children be heard about their perceived quality of life (Table 2).

Table 1. Basic characteristic of celiac children sample

\begin{tabular}{|c|c|c|c|}
\hline Characteristic & Categorisation & $\mathbf{n}$ & \% \\
\hline \multirow{2}{*}{ Gender } & Boys & 47 & $37.60 \%$ \\
\cline { 2 - 4 } & Girls & 78 & $62.40 \%$ \\
\hline \multirow{2}{*}{ Age } & Younger (9-11 years) & 64 & $51.20 \%$ \\
\cline { 2 - 4 } & Older (12-14 years) & 61 & $48.80 \%$ \\
\hline \multirow{2}{*}{\begin{tabular}{c} 
Compliance \\
\cline { 2 - 4 }
\end{tabular}} & Son-strict (some gluten) & 33 & $26.40 \%$ \\
\hline \multirow{2}{*}{$\begin{array}{c}\text { Duration of } \\
\text { disease }\end{array}$} & Short (0-6 years) & 83 & $66.40 \%$ \\
\cline { 2 - 4 } & Long (7-14 years) & 42 & $33.60 \%$ \\
\hline \multirow{2}{*}{$\begin{array}{c}\text { Gastro-intestinal } \\
\text { symptoms }\end{array}$} & Yes & 62 & $49.60 \%$ \\
\cline { 2 - 4 } & No & 63 & $50.40 \%$ \\
\hline
\end{tabular}

Table 2. OR of compliance with gluten-free diet by gender, duration of disease and age of children

\begin{tabular}{|c|c|c|c|c|c|c|c|}
\hline \multicolumn{2}{|c|}{ Characteristic } & $\mathbf{n}$ & Strict diet & $\begin{array}{c}\text { Non-strict diet } \\
\text { (some gluten) }\end{array}$ & OR & 95/CI & $\mathbf{P}$ \\
\hline \multirow{2}{*}{ Gender } & Boys & 47 & $59.6 \%(28)$ & $40.4 \%$ (19) & \multirow{2}{*}{0.32} & \multirow{2}{*}{$0.14-0.73$} & \multirow{2}{*}{$\begin{array}{c}0.007 \\
* *\end{array}$} \\
\hline & Girls & 78 & $82.0 \%(64)$ & $18.0 \%(14)$ & & & \\
\hline \multirow{2}{*}{ Age } & $\begin{array}{c}\text { Younger } \\
\text { (9-11 years) }\end{array}$ & 64 & $76.5 \%(49)$ & $23.5 \%(15)$ & \multirow{2}{*}{1.37} & \multirow{2}{*}{$0.62-3.04$} & \multirow{2}{*}{$\begin{array}{c}0.44 \\
\text { n.s. }\end{array}$} \\
\hline & $\begin{array}{c}\text { Older } \\
\text { (12-14 years) }\end{array}$ & 61 & $70.5 \%(43)$ & $29.5 \%(18)$ & & & \\
\hline \multirow{2}{*}{ Duration of disease } & $\begin{array}{c}\text { Short } \\
\text { (0-6 years) }\end{array}$ & 83 & $71.1 \%(59)$ & $28.9 \%(24)$ & \multirow{2}{*}{1.23} & \multirow{2}{*}{$0.55-2.7$} & \multirow{2}{*}{$\begin{array}{c}0.61 \\
\text { n.s. }\end{array}$} \\
\hline & $\begin{array}{c}\text { Long } \\
\text { (7-14 years) }\end{array}$ & 42 & $66.7 \%(28)$ & $33.3 \%$ (14) & & & \\
\hline
\end{tabular}

\section{Discussion}

The study population of the children was recruited in outpatient clinic of gastroenterology where we couldn't avoid some selection bias. Also data might be limited only with analysis inside of the sample of celiac children patient. We didn't include control group also avoiding to create completely different case-control study with more limited results - if control subjects are not properly selected. The study sample is not large enough and when we go to statistical stratification of the sample we could have problem to obtain statistically significant results. Also some limitations could be in the form of questionnaires which were admitted to children, where could be problem with understanding. We modified questionnaires differently for younger and older age group so to catch maximum understanding of the questions included in the questionnaires.

Mean age of children in our sample group was all over than in the study of Rashid et. al., [7]. Better adhering to gluten free diet in the group of girls and females was also confirmed in the studies of Ciacci et al. 2003 [13]. The above mentioned studies also confirmed several factors connected with reduced health related quality of life: gender, age of diagnosis, teenage diet, absence of symptoms, education of parents and also income per capita in the family. CD is described mostly as a chronic disorder starting in childhood period $[14,15]$. There is described decrease in the incidence of $\mathrm{CD}$ among European children population [16].

\section{Conclusions}

Our study revealed some import social and demographic factors which might influence in adhering very demanding gluten-free diet. Among factors which have been proposed in the past as accounting for real decline of celiac dieses or for delayed diagnosis are changes in infant feeding practices such us prolonged breast feeding, lower antigenicity of baby food formulas and later introduction of gluten in the infant diet. Also quality of life of celiac children has tendency to be improved due wider production of gluten free products and also due food products labelling.

\section{References}

[1] Di Sabatino A, Corazza GR: Celiac disease. The Lancet 2009; 373 1480-1493. 
[2] Kupper C: Dietary guidelines and implementation for celiac disease". Gastroenterology 2005; 128: 121-127.

[3] Treem WR: Emerging concepts in celiac disease. Curr Opin Pediatr 2004; 16: 552-559.

[4] Ciacci C, Lavarone A, Mazzacca G, De Rosa A: Depressive symtoms in Adult Coeliac Disease. Scand J Gastroenterol 1998, 33: $247-250$.

[5] Black JL, Orfilia C: Impact of celiac disease on dietary habits and quality of life. J Hum Diet 2011; 24: 582-587.

[6] Grech PL, Richards J, McLaren S: Psychological sequelae and quality of life in coeliac disease. J Pediatr Gastroenterol Nutr 2000; 31: 6 .

[7] Rashid M, Cranney A, Zarkadas M, Graham ID, Switzer C, Case S, Molloy M, Warren RE, Burrows V, Butzner JD: Celiac disease: evaluation of the diagnosis and dietary compliance in Canadian children. Pediatric 2005; 116:e754-e759.

[8] Hallert C, Grännö C, Hultén S, Midhagen G, Ström M, Svensson $\mathrm{H}$, Valdimarsson T: Living with coeliac disease: controlled study of the burden of illness. Scand J Gastroenterol 2002; 37: 39-42.

[9] Roos S, Karner A, Hallert C: Psychological well-being of adult coeliac patients treated for 10 years. Dig Liver Dis 2006; 38: 177180.

[10] Zarkadas M, Cranney A, Case S, Molloy M, Switzer C, Graham ID, Butzner JD, Rashid M, Warren RE, Burrows V: The impact of gluten-free diet on adults with coeliac disease: results of a national survey. J Hum Nutr Die 2006; 19: 41-49.

[11] Altobelli E, Paduano R, Gentile T, Caloisi C, Marziliano C, Necozione S, Orio F: Health-related quality of life in children and adolescents with celiac disease: survey of a population from central Italy. Health and Quality of life Outcomes 2013; 11: 04

[12] ESPGHAN guidelines diagnosis coeliac disease children/adolescents. An evidence-based approach, CDC 11 November 2010, 30 pp., http://www.celiac-diseaseconsortium.nl/attachments/080_Mearin\%20ESPGHAN\%20CD\%2 0WG\%20voor\%20CDC\%20november\%202010.pdf.

[13] Ciacci C, D'Agate C, De Rosa A, Franzese C. Errichiello S, Gasperi V, Pardi A, Quagliata D, Visentini S, Greco L: Self-rated quality of life in celiatic disease. Digestive Diseases and Science 2003; 11: 2216-2220.

[14] Walker-Smith J, Murch S: Coeliac disease. In Diseases of the small intestine in childhood. 4thed Oxford: United Kingdom, Isis Medical Media Ltd.; 1999, 234-277.

[15] Rimarova K: Celiac diseases - Global demographic context and Slovakia. International Journal of Celiac Disease 2013; 1: 23-26.

[16] Troncone R, Greco L, Auricchio S: The controversial epidemiology of coeliac disease. Acta Paediatr 2000; 89: 1-2. 